\title{
Missing links: Challenges in engaging the underserved with health information and communication technology
}

\author{
Maria D. Wright, RN, BSN¹, Mindy E. Flanagan, $\mathrm{PhD}^{2}$, Kislaya Kunjan, MS, MBA², Bradley N. \\ Doebbeling, MD, MSc ${ }^{3}$, Tammy Toscos, $\mathrm{PhD}^{1,2}$
}

${ }^{1}$ Parkview Research Center, Parkview Health, Fort Wayne, IN; ${ }^{2}$ School of Informatics \& Computing, Indiana University Purdue University, Indianapolis, IN; ${ }^{3}$ School for the Science of Health Care Delivery, College of Health Solutions, Arizona State University, Phoenix, AZ

\begin{abstract}
We sought to understand underserved patients' preferences for health information technology (HIT) and examine the current use of personal health records (PHRs) in Community Health Centers (CHCs) serving low-income, uninsured, and underinsured patients. Forty-three patients and 49 clinic staff, administrators, and providers from these $\mathrm{CHC}$ systems were interviewed using open-ended questions assessing patient experience, perceptions of the $\mathrm{CHC}$, access barriers, strategies used to overcome access barriers, technology access and use, and clinic operations and workflow. All seven $\mathrm{CHC}$ systems were at some stage of implementing PHRs, with two clinics having already completed implementation. Indiana $\mathrm{CHCs}$ have experienced barriers to implementing and using PHRs in a way that provides value for patients or providers/staff. There was a general lack of awareness among patients regarding the existence of PHRs, their benefits and a lack of effective promotion to patients. Most patients have access to the internet, primarily through mobile phones, and desire greater functionality in order to communicate with CHCs and manage their health conditions. Despite decades of research, there remain barriers to the adoption and use of PHRs. Novel approaches must be developed to achieve the desired impact of PHRs on patient engagement, communication and satisfaction. Our findings provide a roadmap to greater engagement of patients via PHRs by expanding functionality, training both patients and clinic providers/staff, and incorporating adult learning strategies.
\end{abstract}

\section{CCS Concepts}

- Applied computing $\rightarrow$ Consumer health • Applied

computing $\rightarrow$ Health care information systems $\cdot$ Applied

computing $\rightarrow$ Health informatics

\section{Keywords}

Patient engagement; health information technology; communication technology; Community Health Centers; underserved; uninsured; underinsured; low income; personal health record; patient portal; patient preferences; patient-centered.

\section{BACKGROUND}

In seeking to meet the Centers for Medicare and Medicaid Services (CMS) Meaningful Use Stage 2 requirements stipulated in the Electronic Health Record (EHR) Incentive Program [8], eligible providers and health systems have made considerable efforts and investments to implement new health information technology (HIT), particularly EHRs with tethered personal health records (PHRs). With increased attention to patient engagement and patient-centered care, patients should have the ability to view, download, and transmit their health information online, as well as communicate with their providers and collaborate in decision making [7]. Accordingly, PHRs tied to an EHR (sometimes called 'patient portals') provide a mechanism by which patients can gain secure, online access to some of their personal health information such as current medications, allergies, laboratory results, immunization history and information on recent clinic visits. Additionally, many PHRs allow for the transmission of secure messages between a patient and a provider [42]. The CMS believes that health care providers are "in the best position to encourage the use of health IT by patients to further their own health" [8]. However, despite nearly two decades of research calling for a focus on improving PHR adoption [22][40] the extent to which providers encourage use and patients engage with the technology continues to be a challenge [29].

In recent years, patient engagement has gained increased attention and awareness by health care industry leaders as a key component of the EHR Incentive Program. Patient engagement encompasses actively involving patients to participate in their own health care [2][5]. Although patients' needs vary greatly, HIT can be used in multiple ways to meet those needs. However, engaging patients through the use of technology is not a simple or surefire process [41]. Many studies have pointed to the importance of identifying the 'perceived value' for patient engagement with the PHR and the importance of tailoring design with a focus on supporting the health action a user can take based on presented data $[4][38][40][36]$.

Underserved populations may require special consideration in the discussion about HIT and patient engagement. When intending to meet the needs of low-income and uninsured or underinsured patients, Community Health Centers (CHCs) are a key point of contact and source of care. CHCs are non-profit organizations that offer primary care services to those with limited access to health care [16]. Services provided at CHCs may include visits with a health care provider, immunizations, health screenings, laboratory and radiology, pharmacy, dental, and mental health services. Services are often provided on a sliding scale based on an individual's ability to pay. In 2014, there were 1278 CHCs in the US, and 23 of those were located in the state of Indiana serving over 393,000 patients, most of whom are racial and/or ethnic minorities, low income, and/or uninsured or underinsured [15].

PHRs have been implemented recently by many organizations that serve uninsured and underinsured populations to meet meaningful use requirements. PHRs have the potential to enhance communication between healthcare providers and patients, 
empower patients, support care between visits, and improve patient outcomes [34]. Their use could potentially decrease call volume, clinical workload, as well as improve clinic efficiency and quality of care [10]. In this paper, we describe opportunities to improve engagement of patients with their personal health information in underserved populations, based on adult learning principles.

\section{OBJECTIVE}

Studies have shown that patients across all socioeconomic classes have access to the internet via smart phones [1] and regularly search for health information online [11]. Here our objective was to understand both use and barriers to use, as well as identify novel approaches to improve access to health care and engage the underserved patient population in their personal health information using pervasive technologies. Thus, our overarching goals were to understand the challenges to and innovative approaches for implementing PHRs in CHCs.

\section{METHODS}

We specifically selected $\mathrm{CHCs}$ for participation from the population of all CHCs in Indiana to be representative of a broad range of geographic, urban versus rural, socio-demographic and race/ethnicity variation. $\mathrm{CHC}$ systems also were chosen based on evidence of a commitment to improve access to care. Semistructured interviews were conducted to assess health care access barriers and uncover patient, provider, and staff-level innovative solutions to overcome access barriers. Interview questions were developed to assess patient experience, barriers to accessing healthcare and strategies to overcome them, technology access/use, and clinic operations/workflow. The institutional review board of Indiana University approved the protocol for this study.

\subsection{Participants}

Interview participants included patients (aged 18+ years), providers, administrators, and staff from seven high-volume $\mathrm{CHC}$ systems in Indiana. Purposive sampling was used to recruit interview participants. Specifically, a clinic manager or upper level manager identified patients who had faced and overcome barriers to healthcare and staff who worked around barriers in the workplace in innovative ways to deliver care. Spanish interpreters were used with Spanish speaking participants when needed.

\subsection{Data Collection}

Data collection took place between January 2014 and February 2015. Interviews were conducted face-to-face by one researcher in each of the seven CHC systems. The interviews were conducted in private rooms and typically lasted 30-60 minutes. All interviews were audio recorded and transcribed. Patient participants were given a \$20 gift card incentive payment to reimburse the time required to participate. $\mathrm{CHC}$ staff and providers were not compensated individually, but rather the $\mathrm{CHC}$ was reimbursed for the time employees dedicated to the interviews during working hours. Written informed consent was obtained prior to the start of each interview.

\subsection{Data Analysis}

Interview data was analyzed using a thematic and iterative approach. Using a grounded theory approach, a team of five researchers independently analyzed the same interview in order to uncover themes. The coding team then compared, discussed, and if necessary, made adjustments to the themes. This process was repeated until the set of themes were stable (not adding new items) and there was agreement in the coding of several transcripts across reviewers. When the coding team was in agreement, the final version of a codebook was determined which contained 38 codes for themes with descriptions and example text. The interviews were then individually analyzed using the final codebook imported into QSR International's NVivo 10 qualitative data analysis software [32]. For these analyses, all segments related to PHR use and health needs between medical visits were collected using NVivo software. We sought consistent themes, differences across different types of settings, and to identify both barriers and innovations identified by one or more participants.

\section{RESULTS}

\subsection{Interview Study Findings}

A total of 92 participants from seven CHC systems completed the semi-structured interviews. The characteristics of the seven $\mathrm{CHC}$ systems are summarized in Table 1 . It is important to note that each of these systems involved from one to many clinic sites, and all sites were using electronic medical records (EMR). Participants consisted of $43 \mathrm{CHC}$ patients and 49 staff in a variety of roles including providers, nurses, medical assistants, schedulers and administrators. The participating $\mathrm{CHC}$ staff members were mostly female $(87 \%)$ and just over half had worked there more than five years $(55 \%)$. The age, race, and insurance status for patient participants are shown in Figure 1.

\subsection{Current State of the PHR - Limited Functionality and Support}

Challenges related to PHR implementation and uses were identified consistently across patient and clinic personnel interviews (e.g., providers, managers, and other clinic staff). Each $\mathrm{CHC}$ was at a different stage in the implementation of their PHR at the time of the interviews: two of the clinic systems had already implemented their PHR, while the remaining five clinic systems were in planning stages with definite plans to implement a PHR in the near future.
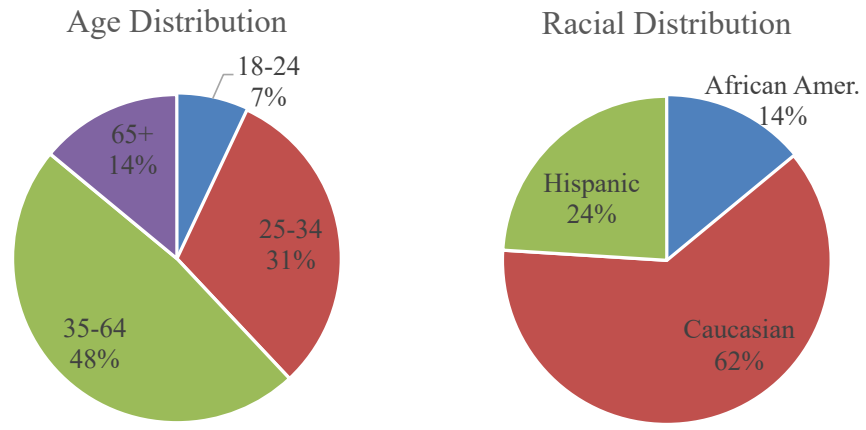

Insurance Status

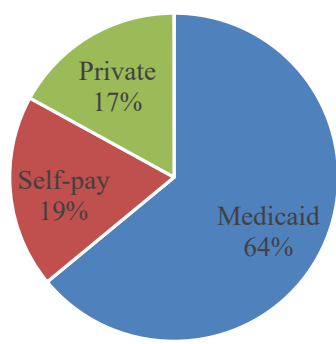

Figure 1. Age, Race, and Insurance Status for Patient Participants 
Table 1. Summary Characteristics of Participating CHC Systems

\begin{tabular}{|c|c|c|c|c|c|c|c|c|}
\hline $\begin{array}{l}\text { Clinic } \\
\text { Site }\end{array}$ & Clinic Specialty & $\begin{array}{l}\text { Clinic } \\
\text { Type }\end{array}$ & $\begin{array}{l}\text { Approx. } \\
\text { Patients } \\
\text { Served } \\
\text { /Year }\end{array}$ & $\begin{array}{c}\text { Stage of PHR } \\
\text { Implementation }\end{array}$ & $\begin{array}{c}\text { Physicians } \\
\text { [FTE] }\end{array}$ & $\begin{array}{l}\text { Total } \\
\text { Staff } \\
{[\text { FTE] }}\end{array}$ & $\begin{array}{c}\text { of } \\
\text { Providers/ } \\
\text { Staff } \\
\text { Interviewed }\end{array}$ & $\begin{array}{l}\text { \# of Patients } \\
\text { Interviewed }\end{array}$ \\
\hline $\bar{A}$ & $\begin{array}{l}\text { Family Medicine, } \\
\text { Pediatrics, OB/GYN, } \\
\text { Behavioral Health, } \\
\text { Dental, Vision }\end{array}$ & Urban & 59,000 & Implemented & 41.04 & 568 & 7 & 6 \\
\hline $\bar{B}$ & $\begin{array}{l}\text { Family Medicine, } \\
\text { Pediatrics, OB/GYN }\end{array}$ & Urban & 42,000 & Planning & 16.6 & 221 & 6 & 5 \\
\hline $\mathrm{C}$ & $\begin{array}{l}\text { Family Medicine, } \\
\text { Pediatrics, Obstetrics, } \\
\text { Dental }\end{array}$ & Urban & 20,000 & Planning & 5.11 & 137 & 7 & 6 \\
\hline $\mathrm{D}$ & $\begin{array}{l}\text { Family Medicine, } \\
\text { Pediatrics, OB/GYN, } \\
\text { Behavioral Health, } \\
\text { Dental }\end{array}$ & Urban & 13,000 & Planning & 6.65 & 108 & 9 & 8 \\
\hline $\bar{E}$ & $\begin{array}{l}\text { Family Medicine, } \\
\text { Dental }\end{array}$ & Rural & 7,500 & Planning & 2.29 & 42 & 9 & 5 \\
\hline $\mathrm{F}$ & Family Medicine & Urban & 7,000 & Implemented & 1.34 & 42 & 5 & 6 \\
\hline$G$ & Family Medicine & Rural & 4,800 & Planning & 1 & 21 & 6 & 7 \\
\hline
\end{tabular}

The uptake of the PHR by patients was slow in the clinics that had already implemented them. Providers and staff recognized that many of their patients were not using the PHR. Nevertheless, they acknowledged that patients often did not have sufficient justifications for PHR use. For example, one nurse stated: "I think some patients, like well-child checks, they're like, OK, I'll sign up, but a lot of them don't really use it because there's not a lot going on. "<S5: Registered Nurse $>$

PHRs have been implemented with limited, initial functionality, such as appointment requests, care summaries, laboratory results, and secure messaging. Both clinic personnel and patients reported desiring PHR functionality not currently offered including: scheduling appointments; refilling prescriptions; completing or updating the health history and registration forms; viewing medical records; accessing educational materials; receiving reminders to schedule appointments, lab tests, immunizations, or routine screenings (e.g., mammograms); smoking cessation support; self-monitoring data (e.g., daily weights from patients with congestive heart failure); telehealth options; even paying a financial balance.

We found CHCs in our sample utilizing PHRs in a limited way for many reasons. First, clinic personnel expressed hesitation and concern about recommending PHRs to patients. For example, staff often had a negative outlook on how the PHR could be used saying that scheduling through the PHR would be too difficult, and patients would ask for last minute refills and appointments. Some believe it would increase their workload, while others have concern about using the PHR to communicate with patients as it is hard to make adjustments to current workflows.

Regarding secure messaging through the PHR, one nurse stated the following: "Now, that is one of those capabilities that I was talking about that isn't used as much yet...We can send them [messages but]...honestly, when we get information... you know, lab results, or whatever, and we need to contact the patient, we go to the phone (laughs). That's still our first method." < 1 : Registered Nurse>

Second, some staff believed that potentially sensitive topics and abnormal test results should be communicated face-to-face rather than through a PHR. Specifically, the quality of communication through a PHR was a concern due to the inability to observe nonverbal communication cues or address a patient's emotional response.

Third, one provider did not see the point of improving the functionality of the PHR because he believed that patients are already using other mobile applications that are more helpful.

\subsection{Missed Opportunities to Educate Patients}

Notably, many patients were not aware of the PHR or its current features. When a patient who had used the PHR was asked if she had downloaded the corresponding application to her phone, the patient responded with surprise:

"They have an app? I've just been using the computer...Shut the front door!" (Interviewer: Would you rather use your phone than the computer?) "I do, because I use my phone for everything. It's my baby. " < 2 : 24 year old female patient $>$

Many CHC providers and staff have not been educated on the use of their PHR. Likely, without proper staff education, patients will not be trained on how to effectively use the PHR. Similarly, some clinics have yet to develop effective processes to communicate how to activate a PHR account:

“...I don't think patients realized - we didn't even realize - that if you don't access your account in 48 hours, then you have to have them reactivate it." $<\mathrm{S} 6$ : Medical Assistant>

Many CHCs miss important opportunities to promote the PHR to patients. Some staff members will bring up the topic with patients, but they expect patients to already be aware of it. One medical assistant said, "I always talk to them, like, 'Are you using the patient portal?' And some will say, 'What's the patient portal?' We have all the signs up..." Even a physician who is accustomed to empowering patients by promoting the use of health-related applications admitted that he had not yet discussed the clinic's PHR with any of his patients: "I actually haven't done that. I probably have to." Some staff admitted that they do not talk to patients about the PHR, and instead they expect other staff members to bring it up with patients. 
"You know what, (laughs), it's so new... I mean, we're using it, don't get me wrong; they get their normal lab results through it and all that. But it's not something I spend a lot of time on because I know that they explain it mostly in the front office." $<$ S1: Registered Nurse $>$

Two clinics had posted flyers telling patients about the PHR, but this written material did not elaborate on the benefits of PHR use. We did not find any specific written materials which explained the PHR to clinic staff or instructed staff how to use it in the CHC setting.

\subsection{Untapped Potential to Address Communication Barriers}

We uncovered potential for the PHR to address expressed needs of patients. First, patients voiced frustrations about making phone calls to the clinic. Patients complained about being put on hold for long periods of time when they call and how it adversely impacts their satisfaction:

"I love to come here, but answering the phones, it takes forever...especially if you're at work, and you're trying to call...It takes forever. They answer the phones. They put you on hold. They can be 20, 25 minutes before they pick up the phone again." $<$ P4: 30 year old female patient $>$

Clinic staff recognized that their phone systems can be inefficient and call volumes can be very large and overwhelming. Staff also reported frustrations with the existing phone systems, which do not support appropriate or effective triaging of calls:

"Staying on hold a long time...I know now, that I'll get voicemails, for calls for appointments that I shouldn't be getting... Or it should have never been sent to my voicemail to ask for an appointment." <S9: Licensed Practical Nurse>

There is a definite need for an alternative method of communication between patients and CHCs. On the other hand, most of the staff were skeptical about the potential use of information and communication technology by their patient population.

"To be honest with you, with the patient portal or anything that has to do with the email, I am a bit skeptical about whether or not they'll check their email unless it's an alert that pops up on their phone... I just question how many patients would actually set their email up on their phone..." <S2: Information Technology Support Staff>

Second, patients need support between visits for health concerns. Providers recognized that the time allotted for appointments with patients with chronic conditions is not adequate to address all health concerns:
"... a lot of times the [patients with a chronic disease] are getting 10 or 15 minute slots, and it's not enough time... That way you rush through the chronic visits, and...You don't want to miss something. The patients feel like they are rushed..." < 9 9: Licensed Practical Nurse >

"The reality is, whether they're medically complex, socially, emotionally complex, patients deserve more time...more than 15 minutes of my time. And it drives me nuts that I have to put a time limit on human need." <S8: Physician Provider>

Third, staff expressed a variety of other general concerns about the use of information technology. Some indicated a fear that technology could take away jobs or replace staff. Others admitted frustrations in the clinic's lack of equipment, software, and technology support. Some staff attitudes were negatively influenced by the inefficiencies related to using technology including: challenges in getting patient records or having to manually enter data from other providers, the amount of time required to use technology, low computer literacy among staff, and the amount of time required to train staff and patients.

Notably, most of the patients we interviewed had access to smart phones and used them to send text messages, email, and access the internet. Patient participants expressed a desire to communicate with the clinic and their providers electronically, and many were open to receiving information from the clinic via text messages and emails. Many are using smartphones to access the internet for a variety of health information, and the use of health-related applications on smartphones was common. Patients would like the option to communicate more easily with their provider about non-urgent concerns between office visits. Patients mentioned needing health-related information on a variety of topics between visits (see Table 2).

\subsection{The Missing Links}

Staff members provided ideas on how to engage patients through a PHR; however, none were currently utilizing those strategies. For example, one provider stated the following:

"It's a great idea, but how do we get the... patients to... get them the motivation to want to even jump on the portal? ...By using messages, uplifting and encouraging, things like that. That's how I think they would engage it. " < S10: Physician Provider $>$

One provider explained the importance of training patients on appropriate expectations for communication, a very important issue that will impact secure messaging through the PHR as it does with phone calls:

“...we have over sixty thousand patients...so, there's only so many people; there's only so much that can be done. You are important to us, but we may not be able to get back to you right within an hour. They can't appreciate that...we do our best." $<$ S10: Physician Provider $>$

Table 2. Health Information desired by patients between visits

\begin{tabular}{ll}
\hline Information Desired & Example \\
\hline Parenting/pediatric information & Immunizations, infant care, child care, developmental progress \\
\hline Pregnancy \& breastfeeding related information & What to expect when pregnant \\
\hline Safety information & First aid, CPR \\
\hline Condition-specific information & On asthma, diabetes, urinary tract infections, etc. \\
\hline Information on medications & $\begin{array}{l}\text { Dosing, medication interactions, what to do when you run out, and general medication } \\
\text { information }\end{array}$ \\
\hline When to go to the emergency department & Unexplained fever \\
\hline Test results & Laboratory results, mammogram results \\
\hline Emotional support & $\begin{array}{l}\text { Related to a patient's anxiety and/or depression, for parents raising a child with } \\
\text { attention deficit hyperactivity disorder }\end{array}$ \\
\hline
\end{tabular}


Another provider talked about the importance of the type and quality of communication that takes place between patients and clinic staff through a PHR:

"To me, it's, who's on the other side of the portal, it's what kind of communication and how do they feel cared for...I think that there has to be somebody on the other side, a live person that they have a relationship with, that they're communicating with about their health needs..." < Quality Manager $>$

\subsection{Study Limitations}

The limitations of this study include the small sample size for the interviews and the limited diversity of our sample of patients, despite selecting clinics based on diversity issues. Additionally, since the clinics were selected based on their interest in solving access to care issues, our findings may be even a best case scenario. Further, at the time the staff interviews were conducted, only two out of the seven $\mathrm{CHC}$ systems had implemented their PHR. The remaining five systems were all in the planning stages of implementation.

\section{DISCUSSION}

Importantly, even in $\mathrm{CHC}$ clinics serving the under- and uninsured, most patients have access to HIT and desire greater functionality in order to communicate with clinical personnel and manage their health conditions. HIT has the important potential to either narrow or widen the disparities that exist in accessing health care [28]. Despite prior assumptions, the underserved patient population has access to the internet through computers and smart phones [1][38]. Similarly, a majority of CHC patients we interviewed have smart phones, and many reported using them as the preferred way to communicate with their healthcare provider. Research suggests that a lack of access to the internet is not the primary barrier to seeking health information among underserved populations [43]. Rather, the digital divide exists at the level of information use and may be the result of a lack of perceived usefulness in addressing individual health needs [4][40][28][37]. Indeed, the patients we interviewed in our study were willing to use a PHR if they perceived value in the interaction. Therefore, the biggest challenge facing health systems that want to engage patients with a PHR is understanding what patients need and value in PHR functionality [4]. Once that functionality is identified and available, the task is to implement well-defined training for patients and staff as well as processes for successful enrollment and sustained engagement.

Table 3. Six assumptions about adult learners [24][25]

\begin{tabular}{ll}
\hline Need to know & $\begin{array}{l}\text { Adults have a need to know why they should } \\
\text { learn something. }\end{array}$ \\
$\begin{array}{l}\text { Self-concept } \\
\text { Role of } \\
\text { experience }\end{array}$ & $\begin{array}{l}\text { Adults have a deep need to be self-directing. } \\
\text { quality of experience than youth. }\end{array}$ \\
$\begin{array}{l}\text { Readiness to } \\
\text { learn }\end{array}$ & $\begin{array}{l}\text { Adults become ready to learn when they } \\
\text { experience in their life situations a need to know } \\
\text { or be able to do in order to perform more } \\
\text { effectively and satisfyingly. }\end{array}$ \\
$\begin{array}{l}\text { Odults enter into a learning experience with a } \\
\text { to learning }\end{array}$ & $\begin{array}{l}\text { task-centered (or problem-centered or life- } \\
\text { centered) orientation to learning. }\end{array}$ \\
Motivation & $\begin{array}{l}\text { Adults are motivated to learn by both extrinsic } \\
\text { and intrinsic motivators. }\end{array}$ \\
\hline
\end{tabular}

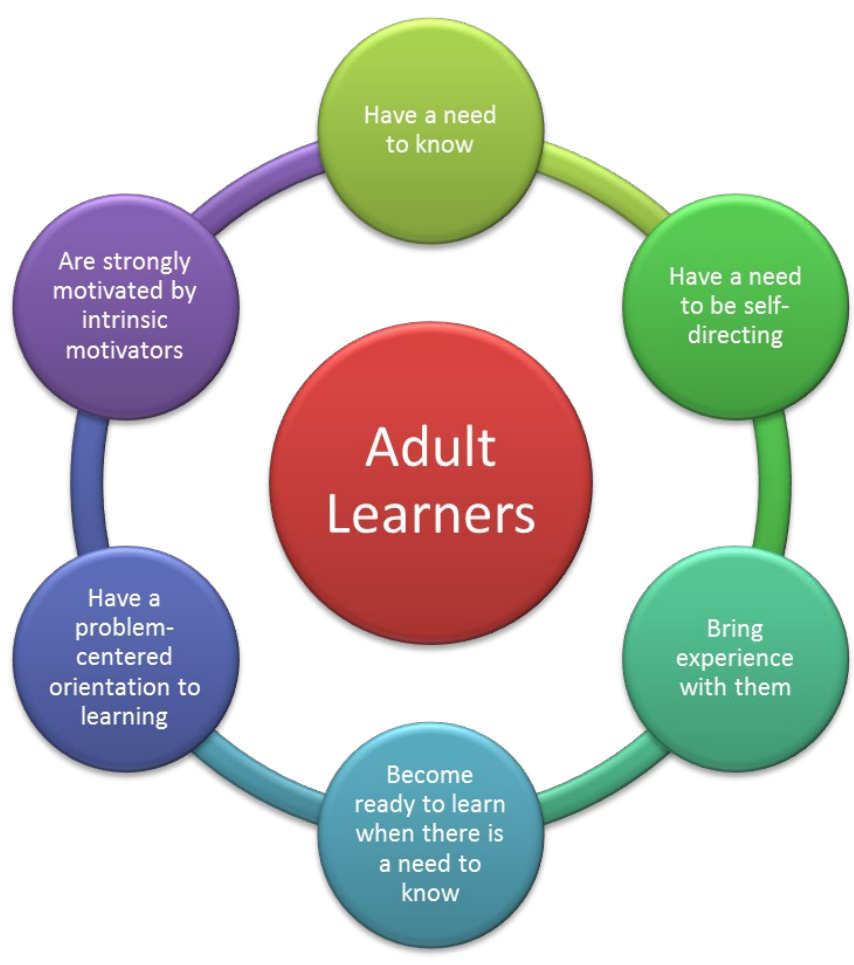

Figure 2. Six assumptions about adults as learners [25]

\subsection{Knowles' Theory of Andragogy}

In order to fully engage users in this form of HIT, patients and clinic personnel may be viewed from a learning perspective that considers their unique and dynamic characteristics. Malcolm Knowles' Theory of Andragogy [22][24][25] is based on six assumptions for adult learners (Table 3, Figure 2) that are relevant to successfully implementing PHRs. Each of these assumptions pertains to underserved adult patients and clinic staff, and may be advantageous when designing and implementing a PHR for underserved populations.

\subsection{Operationalizing Learning Theory for Improved Interaction with the PHR}

In this section we outline each construct of Knowles' Theory and how it can be leveraged to enhance interaction with the PHR.

Need to know - Patients need to know why they should sign up for the PHR, why they should learn how to use it, and why they should keep using it. They have a need to know what the benefits are to learning the new skill versus the costs of not learning it. For example: Will using the PHR ease communication with their provider between appointments? Or will they receive lab results faster than if waiting for a nurse to call?

Self-concept - With various HITs available, patients need to direct themselves and make their own decisions to find the most fitting technologies. We cannot assume that patients would respond positively to using a PHR for interactions with the clinic or their provider. In fact, communication via a PHR may be threatening for some who prefer face-to-face interactions or phone calls. Thus, the PHR can be presented as an optional tool in an array of HITs that can create opportunities for patients to act as agents in improving and managing their own health.

Role of experience - Patients will have a broad range of health and computer literacy skills, experience with technology, relationships with providers and staff, and past experiences at the 
clinic. All of these are potential factors in a patient's use of a PHR. Additionally, patients' ongoing experiences using a PHR may impact future use. The health care provider can be critical in promoting the use of the PHR that supports care between clinic visits. Rolling out the PHR with limited functionality is a safe approach, but the experience of having too little useful information could adversely impact future use.

Readiness to learn - Patients will be ready to learn about and use a PHR when they experience a need to do so, and they will learn best when they voluntarily commit to learning about it. If a patient has a reason to $\log$ in to a PHR, e.g. to get lab values or schedule appointments, they are more likely to want to learn how to use it. We cannot assume a readiness to learn if other satisfactory options are available to the patient. Patients are not going to be ready to learn how to use a PHR just because it is available to them.

Orientation to learning - Most adults are goal-oriented, so they will complete tasks or obtain information that helps them achieve their goals. This orientation reemphasizes the need to understand the types of information that patients seek between appointments to create a reason for logging into their PHR. In our study, patients mentioned needing diverse health-related information between visits (Table 3). Specific attention should be directed at tailoring content for specific groups of patients based on shared goals for health outcomes, e.g. various chronic disease, pediatric, adolescent and pregnant women. In our study population, based on EHR data, we found that mental healthcare needs crossed over nearly all patients. For example, in the largest $\mathrm{CHC}$ of our study, over one-fourth $(27 \%)$ of all the patients had one or more mental health related diagnosis (by ICD-9 CM code regardless of primacy). In contrast, hypertension diagnosis was at distant second with a prevalence of only $9 \%$.

Motivation -In order to tailor PHR content for individuals it may be important to assess the individual's current state of motivation to engage in one's healthcare through a PHR. For example, with low motivation or interest in a PHR, compensation for signing up for the PHR might be necessary. One tool that may be useful in making an assessment is the patient activation measure (PAM). This 13 question survey is a robust and well-validated assessment tool developed by Hibbard and colleagues [18] to measure the level of patient engagement in their health. The PAM is a scale that reflects a developmental model of activation. Activation appears to involve four stages: (1) believing the patient role is important, (2) having the confidence and knowledge necessary to take action, (3) actually taking action to maintain and improve one's health, and (4) staying the course even under stress. PAM scores are independent of traditional socio-economic and demographic such as race, income or education and instead emphasize what the patient can do to help themselves. Hibbard et al. demonstrated that coaching improves PAM scores, medication adherence and reduces re-hospitalization rates [17][18][26].

\subsection{Operationalizing Learning Theory to Engage Clinic Staff}

In this section, we describe how each construct of Knowles' Theory can be used to foster clinic personnel's support of PHRuse among their patient population.

Need to know - Staff and providers have a need to know why they should learn how to use the PHR. For example: Will it make their job easier? And will it help with clinic operations? Staff also need to know the benefits for patients so that they can present information to patients about the PHR and encourage its use.
Self-concept - Staff will likely need to be self-directed in learning about PHR use. Healthcare professionals are often responsible for meeting continuing medical education requirements, in addition to job demands. Offering staff multiple options of how, when, where they can complete training on PHR use will help lower barriers associated with learning how to use the PHR to improve patient experience, and outcomes.

Role of experience - Providers and staff members will also have a broad range of computer literacy skills, experience with technology, relationships with coworkers and patients, and past experiences at the clinic. These experiences may indirectly influence patient use of the PHR. For example, a nurse with poor computer literacy skills may prefer to call a patient with lab results as opposed to encouraging the patient to get the results via the PHR. Staff members who are more engaged in technology outside of clinic are going to have an easier transition incorporating HIT into their daily practice. Therefore, these preexisting experiences and preferences should be considered when tailoring training to staff.

Readiness to learn - Staff will be most ready to learn about a PHR if the technology can help them to perform their job more effectively. If they perceive that they do not really need to use it to do their job, they may be far from ready to learn about it and may avoid using it altogether. In our study, we found staff to be frustrated with the limited functionality of the PHR. This perceived shortcoming may be critical in slow uptake of the technology.

Orientation to learning - Staff will want to be able to apply their new knowledge about the PHR to their practice and interactions with patients. How can using a PHR and encouraging its use by patients help staff reach their goals? Reasons will be different for each individual role or position; this individuality should be considered when implementing a PHR.

Motivation - Clinic staff will want to know how patients benefit from PHR use; and, they will want to know whether the PHR creates more or less effort in their daily work. Thus, when implementing a PHR it is important to engage staff in planning, implementing and communication decisions so they can better understand how it will impact clinic workflow and patient outcomes, offering motivation for use.

\section{CONCLUSION}

In our study, we found patient and clinic personnel perceptions of PHRs differ. Providers and staff verbalize skepticism in using this technology with the underserved population. Despite decades of research, this technology continues to be underutilized and relatively few providers are encouraging patients to use it or explaining why they should use it. We found the PHR is not being properly marketed to the end user and rarely are individual patients walked through the steps to make sure they know how to use the PHR. The underserved patient population has multiple barriers to accessing health care, and our results show that this population has unmet needs. Participants in our study and many others [4][29][36][38][40] have identified many types of desired communication that would add value to PHR interaction, enhancing their healthcare experience and providing actionable data. Our work supports the need for targeted effort towards educating and training both patients and clinic staff.

Patient education has been shown to play a role in patient engagement [9]. Educating patients on why they should do something, how it can help them, and what they can get out of it may help build value in the PHR and impact their rate of use. 
Patients who perceive technological tools to be of value to them have higher intentions to use [42]. Carman et al. [5] contend that patient engagement exists at multiple levels and across a continuum. By looking at patient engagement from these different angles, we can understand it to be a complex and multidimensional concept that can (and should) be addressed from multiple perspectives. We believe that learning theory should be used to inform the processes and support systems put in place by CHCs to encourage the uptake and sustained use of PHRs.

If PHRs are to achieve their desired impact on improved patient engagement, communication and satisfaction, greater efforts are needed. We suggest that PHR implementation strategies should develop an assessment of patient needs, incorporate adult learning principles with both staff and patients, and target programs to better train and engage patients, staff and providers in the use of PHRs. This study was part of a multi-year project after which we will be building a tool-kit for CHCs that will include innovative techniques for engaging patients with their health data. We plan to test our approaches to patient engagement grounded in learning theory in a future study.

\section{REFERENCES}

[1] Anderson, M. 2015, October. Technology device ownership: 2015. [1] Research Center. Retrieved January 15, 2016 from http://www.pewinternet.org/files/2015/10/PI_2015-1029 device-ownership_FINAL.pdf.

[2] Barello, S., Graffigna, G., Vegni, E. and Bosio, A.C., 2014. The challenges of conceptualizing patient engagement in healthcare: A lexicographic literature review. Journal of Participatory Medicine, 6, e9.

[3] Bradley, E.H., Curry, L.A., Ramanadhan, S., Rowe, L., Nembhard, I.M. and Krumholz, H.M., 2009. Research in action: using positive deviance to improve quality of health care. Implementation Science, 4(1), 25.

[4] Brennan, P. F., Downs, S., \& Casper, G., 2010. Project HealthDesign: Rethinking the power and potential of personal health records. Journal of biomedical informatics, 43(5), S3-S5

[5] Carman, K.L., Dardess, P., Maurer, M., Sofaer, S., Adams, K., Bechtel, C. and Sweeney, J., 2013. Patient and family engagement: a framework for understanding the elements and developing interventions and policies. Health Affairs, 32(2), 223-231.

[6] Center for Advancing Health. 2010. Snapshot of people's engagement in their health care. Retrieved 10/08/15 from http://www.cfah.org/file/CFAH_Snapshot_Summary_2010.p df.

[7] Centers for Medicare \& Medicaid Services. 2014, August. Eligible professional meaningful use core measure: Measure 7 of 17. Retrieved October 8, 2015 from https://www.cms.gov/Regulations-andGuidance/Legislation/EHRIncentivePrograms/downloads/Sta ge2_EPCore_7_PatientElectronicAccess.pdf.

[8] Centers for Medicare \& Medicaid Services. 2012, August. Stage 2 overview tipsheet. Retrieved October 8, 2015 from https://www.cms.gov/regulations-andguidance/legislation/ehrincentiveprograms/downloads/stage2 overview_tipsheet.pdf.
[9] Coulter, A., 2012. Patient engagement-what works?. The Journal of ambulatory care management, 35(2), 80-89.

[10] Emont, S. 2011. Measuring the impact of patient portals: What the literature tells us. Retrieved 10/08/15 from http://www.chcf.org/ /media/MEDIA\%20LIBRARY\%20Fil es/PDF/PDF\%20M/PDF\%20MeasuringImpactPatientPortals. pdf.

[11] Fox, S. and Duggan, M. 2013. Health online 2013. Retrieved 01/15/16 from http://www.pewinternet.org/files/oldmedia//Files/Reports/PIP_HealthOnline.pdf

[12] Gallivan J, Kovacs Burns KA, Bellows M, Eigenseher C. 2012 Dec 26. The many faces of patient engagement. $J$ Participat Med, 4, e32.

[13] Gephart, S., Effken, J., Staggers, N., Sackett, K., Hamid, F., Cline, T. and Nagle, L., 2013. Using health information technology to engage patients in their care. Online Journal of Nursing Informatics, 17(3).

[14] Goel, M.S., Brown, T.L., Williams, A., Hasnain-Wynia, R., Thompson, J.A. and Baker, D.W., 2011. Disparities in enrollment and use of an electronic patient portal. Journal of general internal medicine, 26(10), 1112-1116.

[15] Health Resources and Services Administration Bureau of Primary Health Care. 2014 Program grantee comparison data. Retrieved 10/08/15 from http://bphc.hrsa.gov/uds/datacenter.aspx?year=2014\&state=I N\&compare $=$ Nat.

[16] Health Resources and Services Administration Bureau of Primary Health Care. n.d. What is a health center. Retrieved 01/15/16 from http://bphc.hrsa.gov/about/what-is-a-healthcenter/index.html.

[17] Hibbard, J. H., and Mahoney, E. 2010. Toward a theory of patient and consumer activation. Patient Education and Counseling, 78(3), 377-381.

[18] Hibbard, J.H., Greene, J., Tusler, M. June 2009. Improving the Outcomes of Disease-Management by Tailoring Care to the Patient's Level of Activation. American Journal of Managed Care, 15(6), 353-630.

[19] Horan, T.A., Botts, N.E. and Burkhard, R.J., 2010. A multidimensional view of personal health systems for underserved populations. Journal of medical Internet research, 12(3), e32.

[20] Hsu, C.C. and Sandford, B.A., 2007. The Delphi technique: making sense of consensus. Practical Assessment, Research \& Evaluation, 12(10), 1-8.

[21] James, J., Hibbard, J., Agres, T., Lott, R. and Dentzer, S., 2013. Health policy brief: patient engagement. Health Affairs, 33(6).

[22] Kaelber, D. C., Jha, A. K., Johnston, D., Middleton, B., \& Bates, D. W., 2008. A research agenda for personal health records (PHRs). Journal of the American Medical Informatics Association, 15(6), 729-736.

[23] Knowles, M., 1973. The adult learner: A neglected species. Houston: Gulf Publishing Company.

[24] Knowles, M. S., 1980. The modern practice of adult education: From pedagogy to andragogy. Englewood Cliffs: Prentice Hall/Cambridge. 
[25] Knowles, M., 1996. Adult learning. In The ASTD Training and Development Handbook. New York: McGraw-Hill.

[26] Lavsa, S.M., Holzworth, A. and Ansani, N.T., 2010. Selection of a validated scale for measuring medication adherence. Journal of the American Pharmacists Association, 51(1), 90-94.

[27] Long, T., Genao, I. and Horwitz, L.I., 2013. Reasons for readmission in an underserved high-risk population: a qualitative analysis of a series of inpatient interviews. $B M J$ open, 3(9), e003212.

[28] López, L., Green, A.R., Tan-McGrory, A., King, R. and Betancourt, J.R., 2011. Bridging the digital divide in health care: the role of health information technology in addressing racial and ethnic disparities. Joint Commission Journal on Quality and Patient Safety, 37(10), 437-445.

[29] Liu, L. S., Shih, P. C., \& Hayes, G. R., 2011, February. Barriers to the adoption and use of personal health record systems. In Proceedings of the 2011 iConference, 363-370, ACM.

[30] Moore, S.L., Fischer, H.H., Steele, A.W., Durfee, M.J., Ginosar, D., Rice-Peterson, C., Berschling, J.D. and Davidson, A.J., 2014, March. A mobile health infrastructure to support underserved patients with chronic disease. In Healthcare, 2(1), 63-68.

[31] National Committee for Quality Assurance. 2011. Quality profiles: The leadership series - focus on patient engagement. Retrieved 10/08/15 from http://www.nchdcc.org/pdf/RHP4LC-2014.02.20-Workgroup-Handouts.pdf.

[32] NVivo qualitative data analysis software; QSR International Pty Ltd. Version 10, 2012.

[33] Office of the National Coordinator for Health Information Technology. 2013. Personal health records: What health care providers need to know. Retrieved 12/31/15 from https://www.healthit.gov/sites/default/files/about-phrs-forpro.

[34] Office of the National Coordinator for Health Information Technology (n.d.). What is a patient portal. Retrieved October 8, 2015 from http://www.healthit.gov/providersprofessionals/faqs/what-patient-portal.

[35] Patel, V.N., Dhopeshwarkar, R.V., Edwards, A., Barron, Y., Likourezos, A., Burd, L., Olshansky, D. and Kaushal, R., 2011. Low-income, ethnically diverse consumers' perspective on health information exchange and personal health records. Informatics for Health and Social Care, 36(4), 233-252.

[36] Ross, S.E., Johnson, K.B., Siek, K.A., Gordon, J.S., Khan, D.U., Haverhals, L.M., 2011. Two complementary personal medication management applications on a common platform: Case report. Journal of Medical Internet Research, 13(3):e45

[37] Sarkar, U., Karter, A.J., Liu, J.Y., Adler, N.E., Nguyen, R., López, A. and Schillinger, D., 2010. The literacy divide: health literacy and the use of an internet-based patient portal in an integrated health system - results from the Diabetes Study of Northern California (DISTANCE). Journal of health communication, 15(S2), 183-196.
[38] Siek, K. A., Ross, S. E., Khan, D. U., Haverhals, L. M., Cali, S. R., \& Meyers, J. (2010). Colorado Care Tablet: The design of an interoperable Personal Health Application to help older adults with multimorbidity manage their medications. Journal of biomedical informatics, 43(5), S22-S26.

[39] Strasen, T, Johnson S, Toscos T., 2013, November. Engaging patients in underserved populations with health information technology, American Medical Informatics Association Annual Symposium, Washington, DC.

[40] Tang, P. C., Ash, J. S., Bates, D. W., Overhage, J. M., \& Sands, D. Z., 2006. Personal health records: definitions, benefits, and strategies for overcoming barriers to adoption. Journal of the American Medical Informatics Association, 13(2), 121-126.

[41] Toscos, T., Daley, C., Heral, L., Doshi, R., Chen, Y., Eckert, G., Plant, R., Mirro, M., 2016. Impact of electronic personal health record use on engagement and intermediate health outcomes among cardiac patients: A quasi-experimental study. Journal of the American Medical Informatics Association: 23(1), 119-128.

[42] Washington, L., 2014. Enabling consumer and patient engagement with health information. Journal of AHIMA/American Health Information Management Association, 85(2), 56-59.

[43] Zach, L., Dalrymple, P.W., Rogers, M.L. and Williver-Farr, H., 2012. Assessing internet access and use in a medically underserved population: Implications for providing enhanced health information services. Health Information \& Libraries Journal, 29(1), 61-71. 